\title{
PERCEIVED DEPTH AS A FUNCTION OF RELATIVE HEIGHT UNDER THREE BACKGROUND CONDITIONS ${ }^{1}$
}

\author{
WILLIAM EPSTEIN
}

University of Kansas

\begin{abstract}
The hypothesis was proposed, that the perceived depth, which results from the relative height cue, depends on "optical adjacency." A $3 \times 3$ factorial experiment was conducted to examine this hypothesis. The 2 factors were vertical separation (3.5, 5.5, 7.5 in.) and background conditions ( 0 background, outline background without surface texture, textured background). Verbal estimates of the depth between pairs of frontal parallel points were obtained under the 9 conditions. In one experiment, the backgrounds simulated a floor surface, and in another, the backgrounds simulated a ceiling surface. The results in both experiments were comparable. Both main effects, separation and background, and the interaction effect were significant. All the effects were in the direction predicted by the optical adjacency hypothesis.
\end{abstract}

Relative height is often included in general discussions of the cues for perceived depth. The higher of two objects will generally appear more distant. A search of the literature has failed to uncover any systematic experimentation dealing with this cue. Apparently the assertion that there exists a lawful relationship between relative height and relative perceived distance is based on informal observations and demonstrations. Two interesting demonstrations are provided by Gibson (1950, Fig. 72) and Kilpatrick (1952, p. 5). Although these demonstrations, and others like them, may be impressive, an experimental demonstration of this cue under controlled conditions is still desirable.

However, let us assume for the moment that the vertical position cue is valid. What accounts for the effect of this variable? On this question, the experimental literature is also silent. Nevertheless, there are several possible answers, and one of these has been

1 This work was supported by Grant MH 4153 from the National Institute of Mental Health of the United States Public Health Service. examined in the present experiment. The explanation is derived from Gibson's $(1950,1959)$ analysis of the stimulus conditions for perceived space. In Gibson's view, the first step in accounting for the perceived distance of objects is to determine the optical stimulation responsible for the perception of an extended continuous ground surface. Gibson proposes that the optical gradient of textural density is one of the important stimulus correlates of perceived surface. The perceived distance of an object will be determined by its optical relationship to the ground surface, and can be specified by noting at what point, in the textured optic array, the contour of the object interrupts the texture of the ground.

The foregoing analysis provides an explanation of the height-in-the-field cue. Objects which are higher up are normally optically adjacent with portions of the optical gradient of texture correlated with more distant (physically and perceptually) portions of the ground surface, than is the case for relatively lower objects. Therefore, the higher of two objects will appear farther away. Experiments have been 
designed to examine this interpretation.

\section{Experiment I \\ Method}

General plan.-Reports of the perceived depth between a pair of frontal parallel points were obtained. The points were vertically aligned and were separated by one of three vertical interspaces. The prediction was that the depth perceived between the points would increase as the vertical separation increased. The points were observed under three background conditions: zero background, outline background without surface texture, textured background. The expectation was that perceived depth would increase as the specificity of the background (from zero to textured) increased. Furthermore, a significant Separation $\times$ Background interaction was expected. The effects of varying separation were expected to be greater for the highly specific background.

Subjects. - The $S$ s were 30 undergraduates. Ten $S$ s were assigned to each of the three background conditions.

Materials.-The standards were fluorescent points, $\frac{3}{8}$ in. in diameter, located at a disance of $57 \mathrm{in.} \mathrm{from} S$ 's eye. In the completely dark laboratory room they were visible by the light of an ultraviolet tube. The $S$ viewed the points monocularly through a red filter which eliminated any perceptible illumination of the surroundings. Under the condition of zero background, the points were viewed against a black background. For the outline background, the points were fastened onto a frontoparallel black cardboard sheet, on which the trapezoid illustrated in Fig. la was drawn in fluo- rescent paint. The separation between the two parallel sides was 8 in.; the longer of the parallel sides was 26 in.; the shorter, 83 in. The textured background is shown in Fig. 1b. Its outer dimensions were the same as the outline background. Both backgrounds yielded the impression of a receding ground. Figure $1 \mathrm{~b}$ had the appearance of a floor. In addition to these stimulus materials a fluorescent footrule was prepared.

Procedure.-Each $S$ made two verbal estimates of the depth between the points for each of three degrees of vertical separation: $3.5,5.5,7.5$ in. The six trials were run in random order. Each $S$ made judgments under one background condition only. For all background conditions, the absolute heights of the points were the same. The points were located approximately at eyelevel.

The instructions called for a verbal estimate of the depth between each pair of points based on an immediate impression of their depth separation (phenomenal instructions). To facilitate performance, $S$ was shown the fluorescent frontoparallel footrule immediately prior to the depth estimation task. The $S$ was asked to make his judgments in multiples or fractions of a foot. The ruler was not present during the depth estimation task. The instructions also informed $S$ that a report of zero depth was entirely acceptable.

\section{Results}

Table 1 shows the mean perceived depth in inches for each of the nine experimental conditions. In Fig. 2, the means are plotted as a function

TABLE 1

Mean Perceived Depth for Three Vertical Separations under Three Background Conditions

\begin{tabular}{|c|c|c|c|c|c|c|c|c|}
\hline \multirow{3}{*}{$\begin{array}{c}\text { i } \\
\text { Vertical } \\
\text { Separations }\end{array}$} & \multicolumn{8}{|c|}{ Background Condition } \\
\hline & \multicolumn{2}{|c|}{ Zero } & \multicolumn{2}{|c|}{ Outline } & \multicolumn{2}{|c|}{ Textured } & \multicolumn{2}{|c|}{ Overall } \\
\hline & $M$ & $S D$ & $M$ & $S D$ & $M$ & $S D$ & $M$ & $S D$ \\
\hline $\begin{array}{c}3.5 \\
5.5 \\
7.5 \\
\text { Overall }\end{array}$ & $\begin{array}{l}2.11 \\
1.94 \\
2.49 \\
2.85\end{array}$ & $\begin{array}{l}1.88 \\
1.17 \\
2.44 \\
2.05\end{array}$ & $\begin{array}{l}2.12 \\
3.99 \\
5.38 \\
3.83\end{array}$ & $\begin{array}{l}1.27 \\
1.54 \\
2.79 \\
2.37\end{array}$ & $\begin{array}{r}3.08 \\
5.87 \\
12.82 \\
7.26\end{array}$ & $\begin{array}{l}0.90 \\
2.06 \\
3.74 \\
4.79\end{array}$ & $\begin{array}{l}2.45 \\
3.93 \\
6.90 \\
\end{array}$ & $\begin{array}{l}1.53 \\
2.30 \\
4.19 \\
\end{array}$ \\
\hline
\end{tabular}



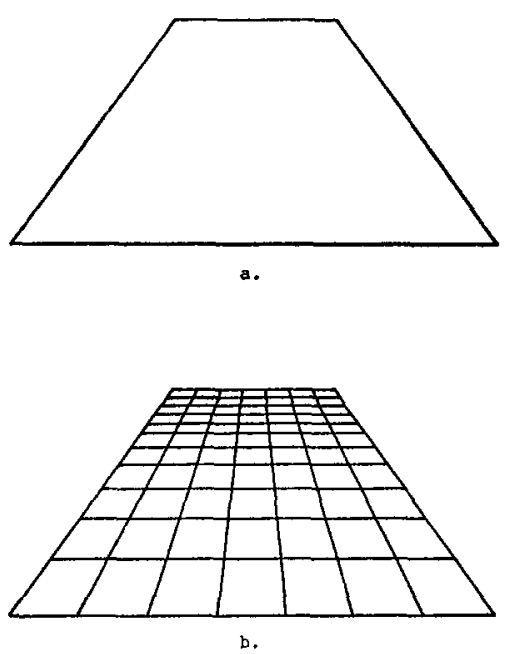

FIG. 1. Outline and textured backgrounds. (The actual dimensions are provided in the text.)

of separation with background as a parameter. An analysis of variance showed that both main effects were significant-separations, $F(2,54)=$ $50.12, p<.001$; backgrounds, $F(2$, $27)=81.80, p<.001$. In addition, the interaction between background and separation was significant, $F(4$, $54)=7.21, p<.001$

The nature of the interaction is easily recognized in Fig. 2 . In the case of zero background, variations in vertical separation did not produce significant differences in perceived depth. And a $t$ test showed that the overall mean perceived depth for the zero background (see Table 1) was not significantly greater than zero perceived depth. On the other hand, with a textured background, each increase of vertical separation produced a significant increase in mean perceived depth. The effects for the outline background were in the appropriate order, but the difference between the 5.5-in. and 7.5-in. separation was not significant.

As another index of the interaction effect, the data were examined to determine the frequency with which $S$ s in each background condition gave depth estimates whose rank order of magnitude agreed with the rank order of magnitude of vertical separation. The number of $S \mathrm{~s}$ in each background condition was 1,4 , and 10 for the zero, outline, and textured background, respectively.

\section{SuPPLEMENTARY EXPERIMENT}

Experiment I was repeated with only one difference. The backgrounds shown in Fig. 1a and 1b were inverted so that a ceiling effect was produced instead of a floor effect. According to the optical adjacency hypothesis this modification should yield only one important difference between the results of Exp. I and the supplementary experiment. The depth effects should be the same except that with the ceiling patterns the lower point should appear more distant.

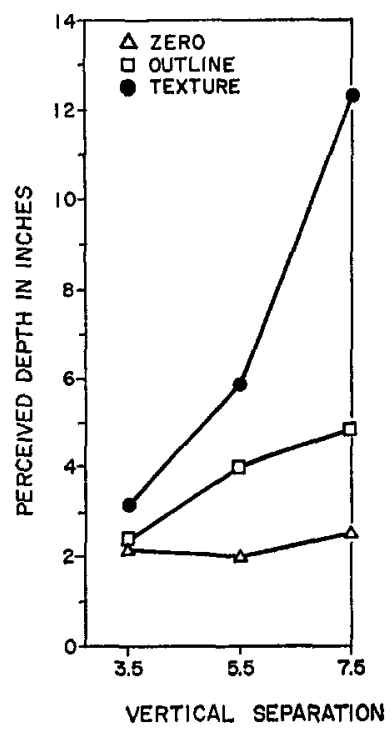

Fig. 2. Perceived depth between the two standards as a function of frontal plane vertical separations and three background conditions. 
Thirty new $S$ s were tested with the ceiling pattern. The main effects and interaction were highly significant in the same direction as Exp. I. The sole difference between the results of the two experiments was the one predicted above. In Exp. I the upper point was judged to be more distant in 79 of the 82 depth reports. (There were 8 reports of zero depth.) In the supplementary experiment it was the lower point that was judged to be more distant in 68 of the 78 depth reports.

\section{Discussion}

The results support the hypothesis of optical adjacency as an account of the effects of relative height on perceived depth. Also, in a general sense, the experiments support Gibson's (1950, 1959) insistence that formulations of the cues for depth should not disregard the surfaces surrounding the object. The cue under discussion is best thought of as relative height in the field rather than relative height or vertical position considered in isolation in empty space. It is also more accurate to omit reference to the direction of the perceived depth, i.e., which appears nearer, unless the background is specified.

Having asserted the importance of background, what can be said about the cases in which, contrary to the results of the present experiment, differences in vertical position produced depth effects in the absence of any visible background. For instance, in Kilpatrick's (1952, p. 5) example, two light points exposed near the ceiling of a dark room are said to appear separated in depth. The same points, also presented in darkness, this time near the floor, are also perceived as separated in depth, but with their positions reversed. To account for these apparent exceptions to the hypothesis of optical adjacency, one further assumption needs to be introduced: In the ab- sence of a visible background, relative height will affect perceived depth, if $S$ assumes the existence of an unseen background. Gibson (1950, p. 180) offers a similar conjecture in his discussion of this cue. There are two ways in which an assumed background can arise. (a) Immediately prior exposure to a background can lead $S$ to imagine or infer its presence when it is no longer visible. The recent study of negative afterimages in "imagined space" (Gruber, King, \& Link, 1963) illustrates an effect of this general nature. (b) Extreme eye or/and head position, normally correlated with distinctively differently oriented surfaces, may induce an assumption of the associated surface when it is not present. Thus, tilting the head back and raising the eyes may create the assumption that the objects are viewed against the ceiling. Since the standard points in the present experiment were located straight ahead, eye position could only signal a frontoparallel wall as the invisible background. According to the optical adjacency hypothesis, variations in vertical separation, which occur in the context of an optic array correlated with a frontal parallel surface, should not lead to perceived depth between the separated points. This would account for the results under the condition of zero background in the present experiment.

\section{REFERENCES}

Grason, J. J. The perception of the visual world. Boston: Houghton Mifflin, 1950.

Grbson, J. J. Perception as a function of stimulation. In S. Koch (Ed.), Psychology: A study of a science. New York: McGraw-Hill, 1959.

Gruber, H. E., King, W., \& Link, S. Moon illusion: An event in imaginary space. Science, 1963, 139, 750-752.

Kilpatrick, F. P. Elementary demonstrations of perceptual phenomena. In F. P. Kilpatrick (Ed.), Human behavior from the transactional point of view. Hanover, N. H.: Institute of Associate Research, 1952.

(Received June 17, 1965) 